\title{
Characterization of serpentinites to define their appropriate use as dimension stone
}

\author{
D. PEREIRA, M. YENES, J. A. BLANCO \& M. PEINADO \\ Depto. de Geología, Universidad de Salamanca, 37008 Salamanca, \\ Spain (e-mail:mdp@usal.es)
}

\begin{abstract}
Many questions arise when considering the appropriate use of building stones such as serpentinites. The commercial names of these rocks, collectively grouped as 'Green marbles', have no correspondence to their actual mineralogy, geochemistry and/or physical characteristics. Serpentinite being the hydrated product of an ultramafic parent rock and not a metamorphic product of limestone as implied by the term 'marble'. However, the serpentinites most widely used for ornamental purposes come from India (e.g. Rajasthan Green, Emerald Green) and in these the original mineralogy has been almost completely converted into carbonates. By contrast, serpentinites from elsewhere (e.g. Vermont Verde Antique from the USA and Verde Pirineos from Spain) do preserve some of their original mineralogy. The different physical and chemical behaviour of carbonates and serpentine minerals can result in significantly different behaviour of commercial building stones. Thus, carbonates are resistant to weathering but suffer from acidic cleaning agents in interior use; whereas serpentinites, with a high content of talc, used on external faces undergo an increase in volume and a consequent rapid degradation.

Accurate and precise characterization of serpentinites, including information on their mineralogy and geochemistry (including major, trace and volatile elements together with oxygen isotopes), in conjunction with their physical properties, would enable architects to select the appropriate interior or exterior use of these handsome building stones.
\end{abstract}

Serpentinites are formed from the transformation of ultramafic rocks (Moody 1976; O’Hanley 1996), with pre-existing anhydrous minerals, olivine, pyroxene, and other Mg-rich silicates and carbonates replaced by assemblages such as calcite/ dolomite-tremolite, calcite/dolomite-diopsidequartz, calcite/dolomite-tremolite-talc, calcite/ dolomite-olivine-diopside-serpentine-brucitemagnetite, etc. The rocks can be partly or totally serpentinized, and therefore exhibit different varieties of textures. To understand the behaviour of serpentinites as ornamental stones, it is necessary to characterize the mineralogy, geochemistry and mechanical properties of these rocks. Serpentinites have been widely used in monuments (e.g. Greek and Italian heritage), and they are very popular in civil construction nowadays (Meierding 2005).

We have studied the serpentinization process of a harzburgite in Cabo Ortegal, NW Spain (Fig. 1, see Díaz García et al. 1999 for a description of the complex). This is one of the ultramafic complexes that is exposed in Spain (the other important one being in the SE of Spain, where the Ronda peridotite crops out: Pereira et al. 2003 and references therein). The fresh rock is mined for refractory material to use in thermic plants, and the serpentinized rock was once traded as dimension stone, with the commercial name 'Verde Pirineos'. The serpentinization process starts by conducting fluids through shears, producing local weathering
(Fig. 2). Fluids involved can be sea water, meteoric water, magmatic water and/or surface-derived hydrothermal fluids (Pereira et al. 2003).

Serpentinization obliterates the primary mineralogy of the rock, and only a few remnants can be identified. Different serpentine phases occur, depending on the transformation conditions (i.e. pressure, temperature, fluid origin). Some rocks show carbonate alteration: the serpentinite has been converted to talc-carbonate paragenesis, and there is no evidence of the previous mineralogy (Fig. $3 \mathrm{a}-\mathrm{c})$. These serpentinites are known commercially as 'Green marbles'. However, if some of the mineral precursors are still in the rock, weathering can affect the rock selectively.

Serpentinites are affected by late shearing, which produced veins filled by calcite. These veins act with different responses to weathering, being weaker than the host rock. The rock can break through these parts once it has been installed as facing stones in a building, thus leading to degradation of the whole slab (Fig. 4).

Serpentinites exhibit a wide spectrum of colours (light-dark green to almost black) and patterns that result from alteration of rock types of diverse bulkrock compositions and structures. The colour of serpentinite also varies with the extent of hydration of the protolith and with the extent of deformation. Once in place, serpentinites can evolve in different ways, depending on their composition. 


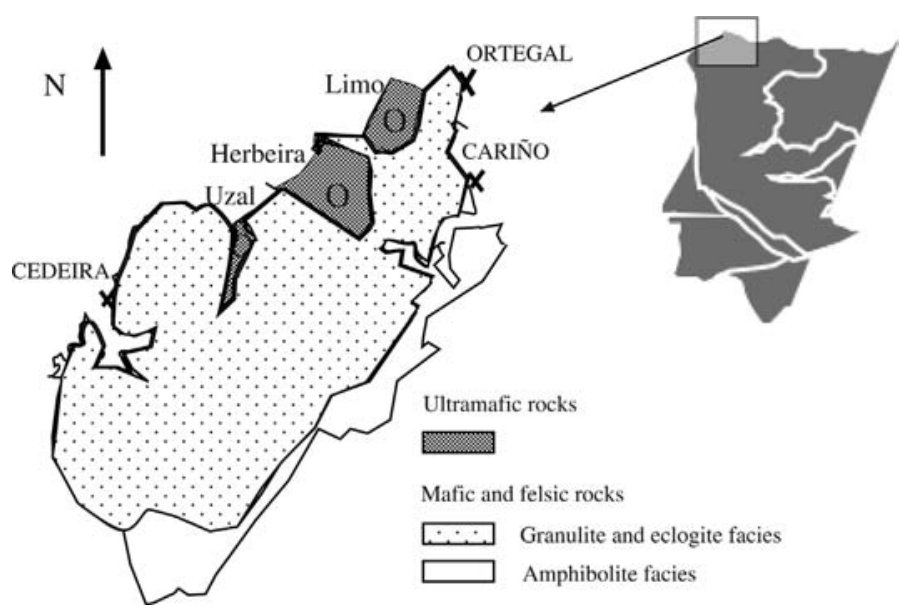

Fig. 1. Location of the Cabo Ortegal complex and the three different massifs studied in this work.

To characterize the serpentinites properly for their use as building stones, their study (and dissemination of results) should include geochemistry, mineralogy and mechanical properties, because all of these parameters strongly depend on the rock, serpentinites being different in different locations (e.g. Verde Macael and Verde Pirineos, from Spain; Verde Alpi and Verde Prato, from Italy; Rajasthan Green, from India). Knowledge of serpentinite behaviour is important not only in monument conservation (Malesani et al. 2003; Marino et al. 2004), but in prevention of rock decay, as this dimension stone is widely used these days in tiling in commercial buildings.

This work includes an example of the characterization of serpentinite from Cabo Ortegal, which explains the behaviour of this rock as building stone.

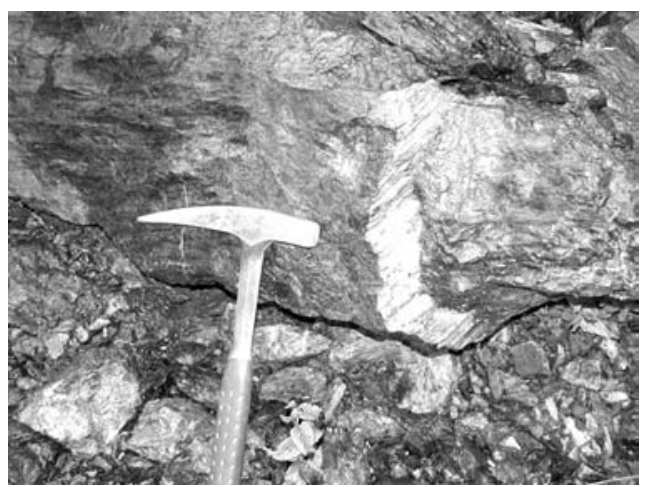

Fig. 2. Serpentinization of ultramafic rocks in Cabo Ortegal. The process starts via shearing, which acts as conduits for fluids.

\section{Mineralogy}

Although a very detailed petrographic study was carried out on thin sections of samples from Cabo Ortegal, it is extremely difficult to distinguish different varieties of serpentine minerals. When serpentinization affects ultramafic rocks severely, only a few remnants of the original mineralogy can be distinguished. Studied samples are formed mainly by several serpentine phases, with relicts of olivine, orthopyroxene presenting many exsolutions, clinopyroxene and chromiferous spinel in different proportions. As accessories green spinel and amphibole were observed. Some phases (e.g. clinopyroxene, amphibole) could have crystallized during metamorphism. The main secondary minerals, besides serpentine, are chlorite, talc and dolomite. From the normative anhydrous composition, most of the samples were determined as harzburgites (except one dunite and one lherzolite).

There should be a correlation between the original lithology and the degree of alteration: dunite (olivine $>90 \%$ ) leads to $100 \%$ altered rock; harzburgite, made of orthopyroxene, leads to less altered rocks (D'Antonio \& Kristensen 2004). Fine-grained rock allows fluids to penetrate and serpentinize. If large orthopyroxene grains are present, then the degree of serpentinization is lower. Microfabric is a very important feature when considering the possible use of serpentinite, because the evolution of any weathering will depend on it.

Carbonated serpentinites present different phases for carbonate substitution. Total carbonate replacement was not found in Cabo Ortegal, this substitution being the most prominent feature in serpentinites from Macael. In these carbonated rocks it is possible to distinguish between a 

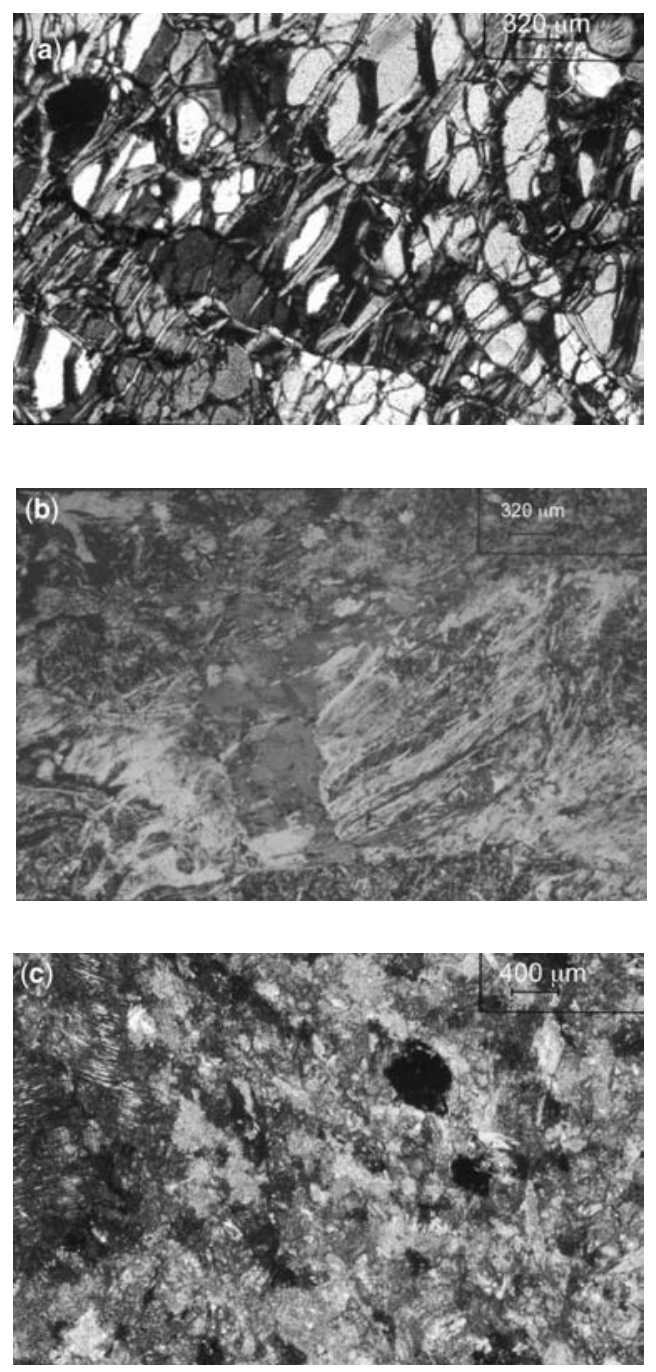

Fig. 3. Changes in mineralogy during a serpentinization process: (a) from $\mathrm{Fe}-\mathrm{Mg}$ silicates; (b) to serpentine phases; (c) to carbonates.

microsparite matrix and the large crystals of sparite filling the fractures. Fabric evidence in these rocks suggests that, although veining and fracture filling predominate, serpentine minerals are extensively replaced by $\mathrm{CaCO}_{3}$. This process, which is probably related to exposure to a circulating fluid, has to be studied in detail, together with its consequences, as it could be the key property in the behaviour of a serpentinite as ornamental stone.

$\mathrm{X}$-ray diffraction was used in the study of some of the samples to distinguish the main components of serpentinization, taking into account that some accessory minerals are present in a quantity below $2 \%$ and
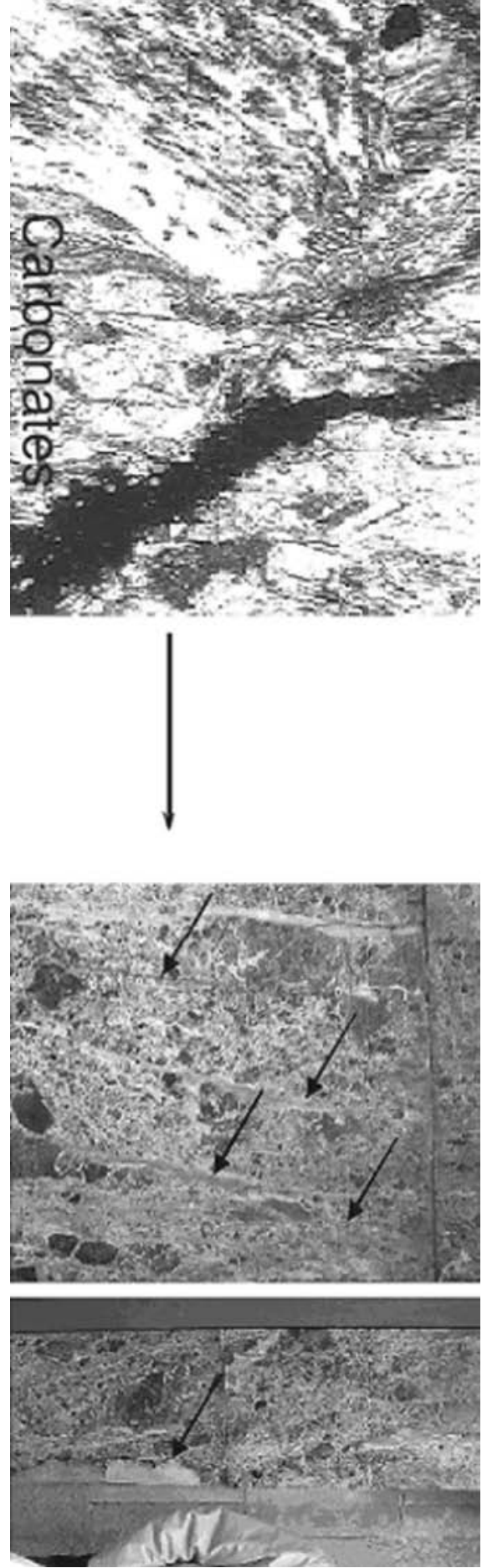

Fig. 4. Shear affecting a serpentinite building stone. Carbonates filling the shear develop a weakness that ends by cracking the tile. 
might not be detected by diffraction. The proper characterization of the secondary minerals is very important for our purpose. In very fresh rocks forsterite, enstatite and tremolite were found as the main mineral phases. The weathered samples contain lizardite and in some of them dolomite has been observed (Fig. 5a). A polishing treatment will be different in samples containing only one mineral phase (or phases from the same group) to those made up of several phases: serpentine, talc, carbonates and spinel. The evolution of the ornamental stone once it has been emplaced in a building will be different as well. X-ray diffractograms can help to find minerals other than serpentine (Fig. 5b). The weathering of different phases can result in the disintegration of the rock. Knowing the presence of such phases can facilitate prior treatment of the rock or the decision to use the ornamental rock for a different purpose subject to less aggressive weathering.

\section{Geochemistry}

The chemistry of serpentinization depends on the origin of the fluid causing the weathering. Although some authors have not found a major variation in the serpentinization process (Mével 2003 and references therein), an opposite conclusion was arrived at here by comparing fresh to weathered samples in the same massif (Tables 1 and 2). Serpentinization introduced changes in the geochemistry of the rocks, both in major and trace elements (including rare earth elements and volatiles such as B and $\mathrm{Cl})$. Stable isotopes are changed as well, and these are very good tracers for the nature of the weathering fluid. At Cabo Ortegal values indicating hightemperature interaction with surface-derived fluids were found, together with values suggesting the evolution of hydrothermal fluids with a more complex history that could involve a mixture with igneous origin fluids. Although most of the serpentinization processes found in the literature call for sea water as the main fluid involved in the process, it is not thought to be the case for Cabo Ortegal serpentinization, where there is no clear enrichment in $\mathrm{Sr}$, which is the key element pointing to a sea-water interaction.

It is apparent that some of the changes are dependent on the nature of the precursor, and knowing the original rock gives a clearer picture of the evolution of weathering. Once the rock has been emplaced as tiles or in any other function as ornamental stone, if it is under different conditions such as very humid conditions, or acid rain or an otherwise contaminated atmosphere, the weathering process can continue on the rock, the same as it would as if it were in outcrop. Therefore, precautions must be taken to avoid the disintegration of the rock. However, if the damage is severe and there is a need for replacement, knowing the geochemistry of the serpentinite would help us to find out where it comes from, so

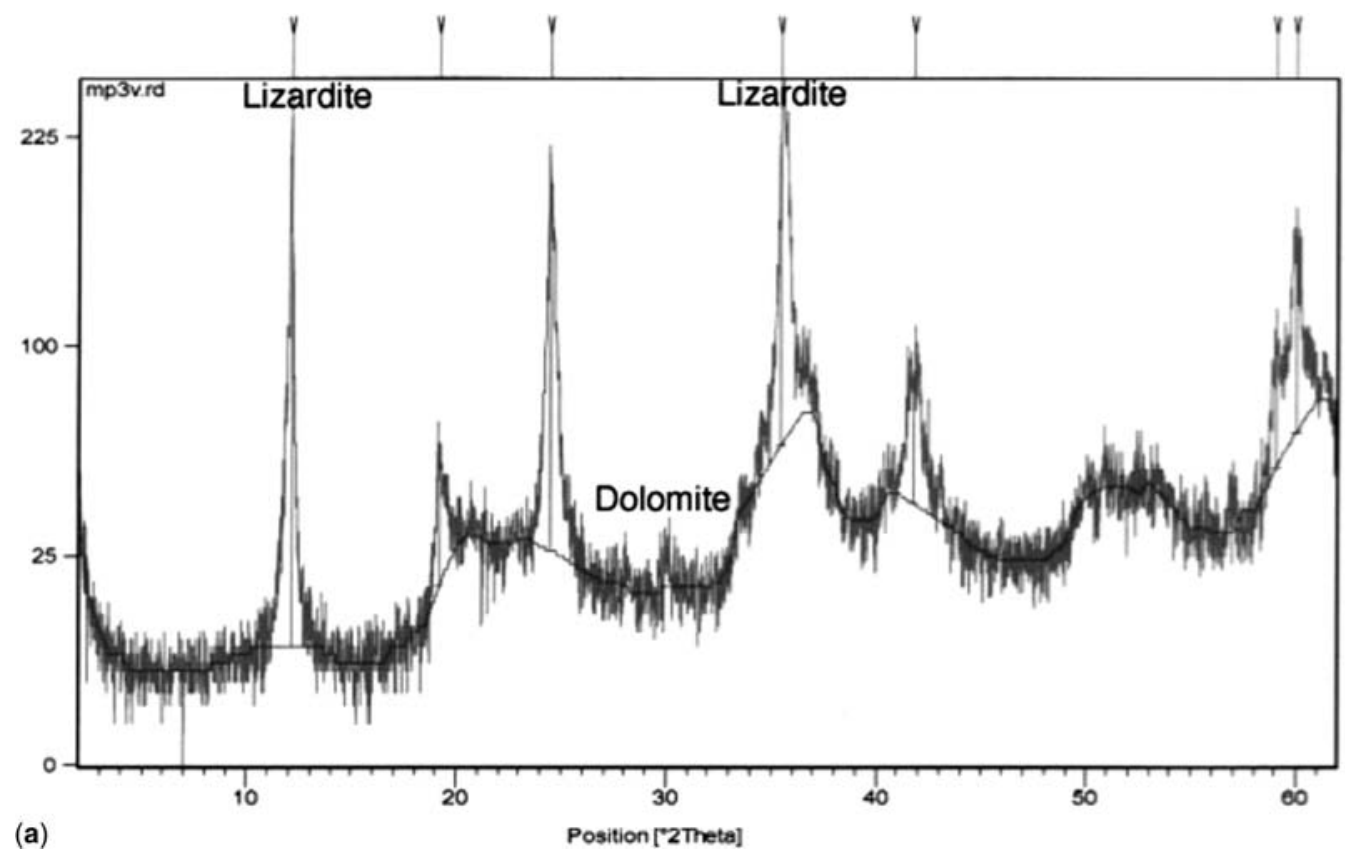

Fig. 5. X-ray diffraction differentiates the different serpentine phases (a) and relicts of the original mineralogy (b), which makes it easier to recognize the possible source of the dimension stone. 


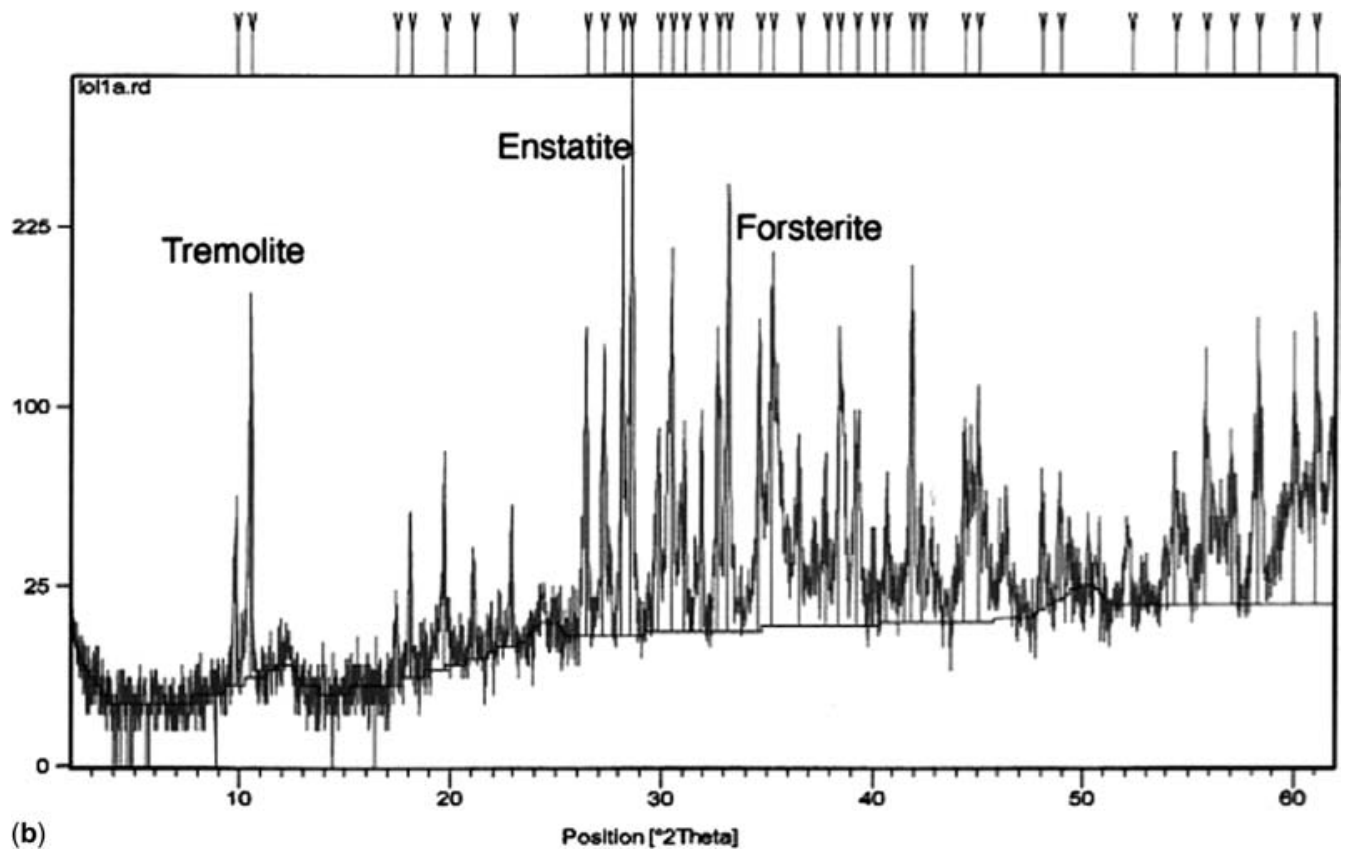

Fig. 5. Continued.

that a similar rock could be used to minimize any changes in the general aspect of the building or structure affected by the weathering (Malesani et al. 2003; Marino et al. 2004). For example, serpentinites coming from Macael (Verde Macael, SE Spain) have undergone a complete transformation to carbonates, and that is reflected in their geochemistry (Table 3). Serpentinites coming from Moeche (Verde Pirineos, NW Spain) are totally transformed to serpentine phases, and only a few mineral precursors are preserved. The geochemistry of a totally serpentinized rock differs from that of a talc-carbonate converted serpentinite. It may also have a different evolution during the in situ meteoric weathering, related to mineral and volume changes.

Stable isotopes can be good tracers for the origin of serpentinites. Wenner \& Taylor (1973) came to the conclusion that, depending on the mineralogy of serpentinites, these should be described either as 'continental' or 'oceanic'; however, Tzen-Fu et al. (1990), taking as a basis stable isotopes, suggested that the domains proposed by the former authors should be extended. In ornamental

Table 1. Major element composition of samples from Cabo Ortegal

\begin{tabular}{lcccccccccr}
\hline Ref. & $\mathrm{SiO}_{2}$ & $\mathrm{TiO}_{2}$ & $\mathrm{Al}_{2} \mathrm{O}_{3}$ & $\mathrm{FeO}$ & $\mathrm{MnO}$ & $\mathrm{MgO}$ & $\mathrm{CaO}$ & $\mathrm{Na}_{2} \mathrm{O}$ & $\mathrm{K}_{2} \mathrm{O}$ & LOI \\
\hline Ort-A & 41.73 & 0.04 & 2.48 & 8.41 & 0.10 & 38.31 & 2.05 & 0.06 & 0.00 & 8.44 \\
Ort-B & 41.33 & 0.09 & 2.46 & 8.12 & 0.09 & 37.50 & 2.51 & 0.06 & 0.00 & 7.35 \\
Ort-C & 38.99 & 0.00 & 1.06 & 8.06 & 0.05 & 38.09 & 0.11 & 0.06 & 0.00 & 13.46 \\
Ort-D & 40.35 & 0.04 & 2.19 & 8.63 & 0.08 & 39.03 & 1.04 & 0.07 & 0.00 & 8.89 \\
Ort-F & 38.59 & 0.05 & 1.67 & 8.68 & 0.12 & 37.92 & 1.34 & 0.06 & 0.00 & 11.61 \\
Ort-S & 40.63 & 0.03 & 1.11 & 9.37 & 0.11 & 41.38 & 0.69 & 0.07 & 0.01 & 7.16 \\
Ort-25 & 40.54 & 0.07 & 2.52 & 8.70 & 0.12 & 37.49 & 1.97 & 0.06 & 0.00 & 7.80 \\
Ort-26 & 42.99 & 0.13 & 3.57 & 7.96 & 0.08 & 34.23 & 5.01 & 0.04 & 0.06 & 4.74 \\
Ort-29 & 42.78 & 0.07 & 3.21 & 8.22 & 0.10 & 37.26 & 2.93 & 0.06 & 0.00 & 4.74 \\
O-718 & 34.83 & 0.01 & 0.19 & 11.37 & 0.18 & 40.09 & 0.02 & 0.07 & 0.01 & 14.46 \\
O-724 & 43.71 & 0.08 & 2.67 & 8.27 & 0.10 & 35.60 & 2.23 & 0.04 & 0.07 & 7.00 \\
O-730 & 43.75 & 0.08 & 3.44 & 7.78 & 0.09 & 33.83 & 3.37 & 0.05 & 0.03 & 7.64 \\
Limo-1 & 42.02 & 0.07 & 3.07 & 8.15 & 0.10 & 34.90 & 2.49 & 0.05 & 0.02 & 9.10 \\
\hline
\end{tabular}

LOI, loss on ignition. 


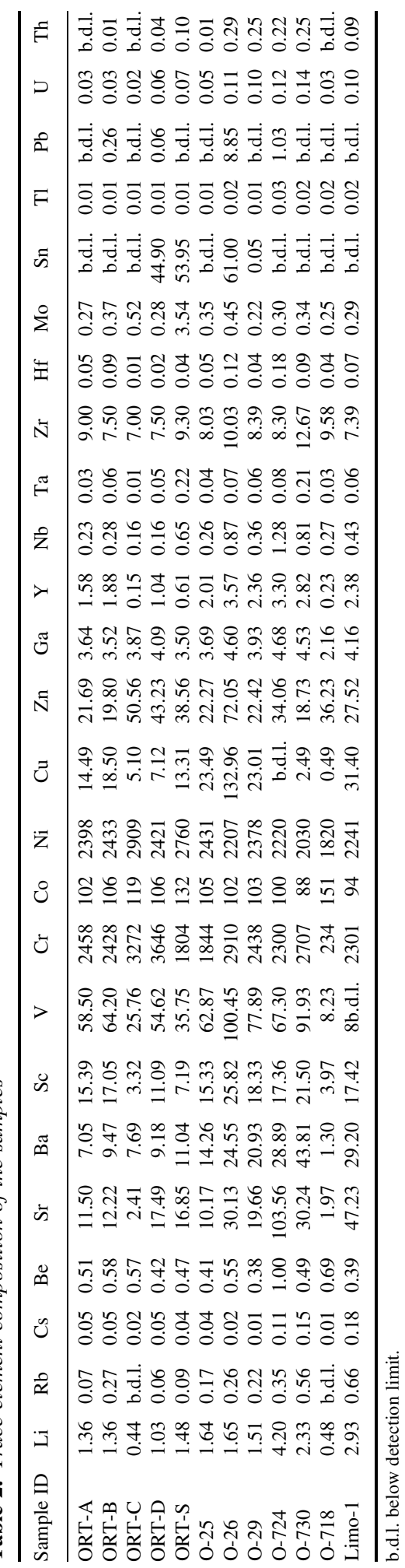

Table 3. Major elements in Spanish rocks: a totally serpentinized rock from Moeche (Galicia) and a carbonated serpentinite from Macael (Andalucía)

\begin{tabular}{lcc}
\hline & Verde Macael* $^{*}$ & Verde Pirineos $^{\dagger}$ \\
\hline $\mathrm{SiO}_{2}$ & 0.17 & 38.99 \\
$\mathrm{TiO}_{2}$ & 0.01 & 0.00 \\
$\mathrm{Al}_{2} \mathrm{O}_{3}$ & 0.00 & 1.06 \\
$\mathrm{FeO}$ & 0.28 & 8.06 \\
$\mathrm{MgO}$ & 0.07 & 38.09 \\
$\mathrm{MnO}$ & 0.15 & 0.05 \\
$\mathrm{CaO}$ & 49.64 & 0.11 \\
$\mathrm{Na}$ & 0.06 & 0.05 \\
\hline
\end{tabular}

*Source: http://www.dipalme.org.

This work.

serpentinite, the real stable isotopic signature probably includes not only the primary values of the rock, but the addition of these plus the changes introduced by meteoric water and the isotopic values of environment and anthropogenic influence. Experiments on changes in isotopic composition in serpentinites from different origins can give useful results in terms of source identification.

\section{Technical properties}

Mechanical strength depends, amongst other factors, on the available anisotropic surfaces. This is why any mechanical characterization has to take into account the orientation of these surfaces regarding the direction of applied efforts. Cabo Ortegal serpentinites show local anisotropies that can change their mechanical behaviour. In this work, selected physical properties of non-oriented samples were determined as a first evaluation of their usefulness as ornamental rock. Future studies will have to deal with oriented samples, to study the changes in properties related to anisotropy.

Owing to the lack of a European specific standard for serpentinites, the physical properties of some of these rocks used as dimension stone were compared with the ASTM standards (C-1526-02, ASTM 2002). This standard specifies the minimum requirements for a serpentinite to be used as ornamental stone, either for interior or exterior use. Parameters analysed in Cabo Ortegal are shown in Tables 4 and 5, together with some other serpentinites from Spain and elsewhere. Absorption according to ASTM C-97 (ASTM 2002), compressive strength according to ASTM C-170 (ASTM 2002) and flexural strength according to ASTM C-880 (ASTM 2002) values are essential for understanding the poor behaviour of the Spanish Verde Pirineos. The serpentinization degree of the rock is generally correlated to the 
Table 4. Physical properties of commercial serpentinites compared to the ASTM requirements

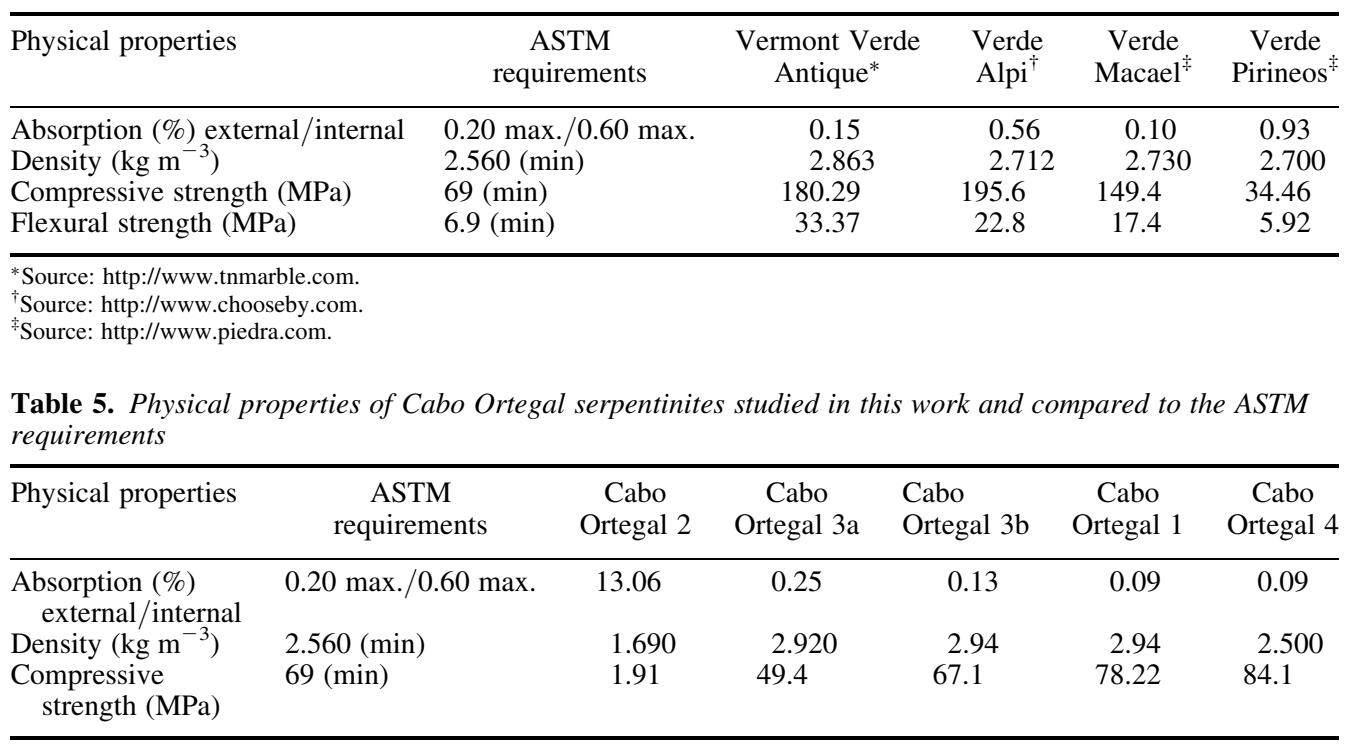

absorption value. Sample 2 presents a highly weathered aspect in hand specimen, and shows the highest absorption values, clearly outside the requirement values. However, sample $3 \mathrm{a}$, which did not show a highly weathered aspect in the field, gave an absorption value of $0.25 \%$, which does not favour its use for exterior tiling. Samples $1 \mathrm{~b}$ and 4 have very low absorption values, but they cannot be classified as serpentinites because the hydration is not enough in these rocks, and they preserve most (80-90\%) of the original mineralogy (olivine, enstatite and spinel) besides serpentine and some tremolite.

There is also a negative correlation between absorption and compressive strength (taking into account that the samples were tested without orientation). Sample 2 presents a very low value for compressive strength and very high absorption value. Sample 3a has a low absorption value and a compressive strength value that does not recommend its use as dimension stone. The rest of the samples reach the minimum physical requirements, where higher compressive strength values are associated with lowered absorption values. This correlation is significant because a first approach to the possibilities of using a serpentinite for ornamental purposes could be tested using the absorption study, which is easy, quick and cheaper, before testing other properties.

\section{Discussion and conclusions}

Serpentinites can suffer a range of changes when exposed to atmospheric conditions (Meierding
2005). To avoid unexpected behaviour of serpentinites used as building stones, a complete characterization of the rock, with data regarding their mineralogy, geochemistry and mechanical properties, should be available. The mining of serpentinites from NW Spain has stopped very recently (Marmolera Gallega pers. comm.). The dimension stone coming from that location, in Moeche, was known as 'Verde Pirineos'. The main reason for stopping the mining appears to have been the poor behaviour of a rock that crumbles very easily, through the lack of any component (e.g. carbonated cement) to hold all the other phases together. In Macael, carbonates hold the serpentine minerals in place and they do not break so easily. The weathering of different phases can lead to the disintegration of the rock. If the presence of such phases is known, the rock can be treated or the decision can be made to use the ornamental rock for a different purpose with less aggressive weathering.

The geochemistry of serpentinites can help to characterize the rock properly, and can be used to create an 'identification card' for the rock. Major and trace elements vary substantially, depending on the precursor of the rock. By knowing the chemistry of the serpentinite, it is possible to obtain a petrogenetical picture of the outcrop from which it could come. This would help in the conservation process of the rock, including replacement. Analyses of stable isotopes can also serve as a possible experiment to see how the atmospheric changes and the meteoric water (and other fluids) to which the rock may be subjected will affect the evolution of the serpentinite once placed as tiling. 
X-ray diffractograms can help to find minerals other than serpentine. This technical approach can aid in identifying the possible source of an ornamental serpentinite, as some of these rocks are mined from massifs with different petrogenesis, and therefore different mineralogy and different mineralogical evolution.

Physical properties for these rocks are very relevant, as they may fulfil the requirements for interior use, but not for exterior use. Some countries do not have a specific standard values table for serpentinites, and they follow the requirements for marbles. It must be insisted that in origin they are not marbles, and, therefore, mineral precursors can be found in them that change some properties, especially absorption, abrasion resistance and even flexural strength. It is recommended that ASTM requirements for serpentinites (ASTM 2002) should be followed. This decision will help to avoid any unexpected behaviour of the stone when used in construction.

It would also be desirable to include the proper petrological name in any description or classification. Including serpentinites within marbles ('green marble') can lead to their incorrect use as building stones. Although some companies suggest the same applications for marbles and limestones, they do not recommend their use as polished surfaces. But the latter purpose is the most common one for this rock, because it shows off all the beauty of the colours (as can be seen in monuments from Greece and Italy). The problems with polishing can be overcome by knowing the correct mineralogy of the rock.

It is proposed that commercial companies should submit a complete characterization of the rock, with data regarding its mineralogy, geochemistry and physical properties. It is also suggested that large commercial companies maintain a 'Geology' section that would advise on the proper use of the rock, together with the possible consequences regarding the behaviour of the rock if the recommendations are not followed. Although this could be expensive for the company, it would be compensated for by offsetting any economic punishment attached to the wrong characterization of the stone when exporting to countries with severe restrictions (US Customs 2001). In addition, it would be a desirable tool for studying building façade deterioration, distress, normal aging, and the possibility for innovation in the maintenance, repair and replacement of degraded serpentinite used as dimension stone.

This work has been funded by Projects BTE 2003-04812 and CGL2005-03048/BTE from the Spanish government.
Comments by R. Přikryl, R. Sandrone and an anonymous reviewer helped to improve the manuscript.

\section{References}

ASTM. 2002. Standard Specification for Serpentine Dimension Stone. C 1526-02. ASTM International, West Conshohocken, PA.

D'Antonio, M. \& Kristensen, M. B. 2004. Serpentine and brucite of ultramafic clasts from the South Chamorro Seamount (Ocean Drilling Program Leg 195, Site 1200): inferences for the serpentinization of the Mariana forearc mantle. Mineralogical Magazine, 68, 887-904.

Díaz García, F., Arenas, R., Martínez Catalán, J. R., González del Tánago, J. \& Dunning, G. R. 1999. Tectonic evolution of the Careón ophiolite (Northwest Spain): A remnant of oceanic lithosphere in the Variscan belt. Journal of Geology, 107, 587-605.

Malesani, P., Pecchioni, E., Cantisani, E. \& FratinI, F. 2003. Geolithology and provenance of materials of some historical buildings and monuments in the centre of Florence (Italy). Episodes, 26, 250-255.

Marino, L., Corti, M., Coli, M., Tanini, C. \& Nenzia, C. 2004. The 'Verde di Prato' stones of cathedral and baptistery of Florence. (Abstract.) In: 32nd IGC Florence, T16.03.

Meierding, T. C. 2005 Weathering of serpentine stone buildings in the Philadelphia, Pennsylvania, region: A geographic approach related to acidic deposition. In: Stone Decay in the Architectural Environment. Geological Society of America, Special Paper, 390, 17-25.

MÉvel, C. 2003. Serpentinization of abyssal peridotites at mid-ocean ridges. Comptes Rendus Geosciences, 335, 825-852.

Moody, J. B. 1976. Serpentinization: a review. Lithos, 9, $125-138$.

O’Hanley, D. 1996. Serpentinites. Oxford University Press, New York.

Pereira, D., Shaw, D. M. \& Acosta, A. 2003. Mobile trace elements and fluid-dominated processes in the Ronda peridotite, Southern Spain. Canadian Mineralogist, 41, 617-625.

Tzen-Fu, Y., Hsueh-Wen, Y. \& Chinming Wang, L. 1990. A stable isotope study of serpentinization in the Fengtien ophiolite, Taiwan. Geochimica et Cosmochimica Acta, 54, 1417-1426.

US Customs. 2001. Classification of Marble. What Every Member of the Trade Community Should Know About. Informed Compliance Publication, US Customs Service, Washington, DC.

Wenner, D. B. \& TAYLOR, H. P. 1973. Oxygen and hydrogen isotope studies of the serpentinization of ultramafic rocks in oceanic environments and ophiolite complexes. American Journal of Sciences, 273, 207-239. 